\title{
PLANT-DERIVED CHEMOTHERAPEUTICS DRUGS FOR CANCER CHEMOTHERAPY
}

Alexandra Dragoi ${ }^{1}$ and Oana Alexandru ${ }^{2 *}$

\begin{abstract}
Cancer chemotherapeutic drugs acts in different manner to kill malignant cells. Most of the anticancer drugs available in clinical practice to treat cancer patients, are natural products including whole plant extract, crude plant extracts, isolated constituents, plant -based drug formulations etc. These natural compounds have been a basis for the development of several drugs against cancer. Agents such as topotecan, taxol, vinca alkaloids (vincristine, vinblastine, vinorelbine and vindesine), are important anticancer agents in widespread clinical use. Other agents, such as combretastatin, flavopiridol, betulinic acid were shown to have anti-tumor effects in both in vitro and in vivo experiments.

In this review, we aim to make a brief description of classical plant-derived chemotherapeutics drugs and also to highlight the importance of these natural compounds in the development of new potential drugs in cancer treatment.
\end{abstract}

Keywords: Chemotherapy, cancer, Natural products.

1 University of Medicine and Pharmacy of Craiova, Faculty of Medicine, Romania

${ }^{2}$ Neuropsychiatric Hospital of Craiova, Craiova, Romania

"Corresponding author: Oana Alexandru (oanale@hotmail.com)

Published online: 2 September 2020

\section{Introduction}

Cancer is an important cause of death worldwide. Although in the last decades the prevention methods and the tools of diagnosis improved very much along with the treatment options the burden of cancer remains high. According to the National Cancer Institute, the mortality of the patients diagnosed with cancer is 163.5 per
100,000 per year, a number which is $26 \%$ in decline when compared with the death rates from 1991(1). The disease still represents a continuous battle and the same American agencies estimated that in 2018 1,735,350 new cases of cancer will be diagnosed in the United States. In the low and middle-income countries the situation is more severe cancer being the leading cause of morbidity and mortality(2). In 2018, the most common types of cancers were: breast cancer, lung cancer, prostate cancer, colon and rectum cancer, melanoma, bladder cancer, non-Hodgkin lymphoma, kidney cancer, leukemia, pancreatic cancer, thyroid cancer, and liver cancer (2).

Starting from these data, it is obvious that in the next years the costs will increase 
in order to provide the best standards of care for these patients. Actually, the methods for the treatment of cancer are: surgery, radiotherapy, chemotherapy, immunotherapy, cancer vaccination, the use of stem cells, or photodynamic therapy. Sometimes, these therapies are used alone but often the clinicians are forced to use combinations of therapies which increases the side effects(3). However the treatment options are selected in accordance with the type, location and of course the stage of the tumor.

It is already known that the actual therapeutic methods have limitations regarding the toxicity, bioavailability, nonspecificity, fast clearance and low prevention of metastasis(4). Therefore, the development of some new anticancer drugs which are less expensive, safer and with minimal side effects is a nowadays target. In ancient times the traditional herbal medicine represented the main treatment option for the people diseases. It is known today that the plants contains phytochemicals that have pharmacological functions. Also, some plant products are involved in the inhibition of some cancer proteins, enzymes, signaling pathways, or in the activation of DNA repair mechanism, protective enzymes or antioxidant mechanism(5). In our review we aim to present some plant products used in cancer treatment, to make a brief characterization of classical plant-derived chemotherapeutics drugs and also to highlight the importance of these natural compounds in the development of new drugs with clinical potential in cancer treatment.

\section{Current anticancer medicines based on natural products}

Vinka alkaloids. The first plant derived anticancer drugs which were used in clinic were vinka alkaloids. Actually, these are natural alkaloids extracted from the leaves of Catarantus roseus (formerly known as Vinca rosea) plant which was initially found in Madagascar but also in Jamaica and Philippines. First, it was observed that the extract obtained from the leaves reduced white blood cells counts and caused bone marrow depression(6). The main representants of the class are vincristine and vinblastine. The antitumor mechanism of these natural compound is by inhibiting the polymerization of tubulin $(7,8)$. Vincristine main use is for acute lymphoblastic leukemia treatment, but it was also used as chemotherapy for other lymphomas, Kaposi's sarcoma, neuroblastoma, breast cancer, lung cancer, testicular cancer, nephroblastoma, and so on (9). Because the extract of these natural alkaloids is very expensive, some semisynthetic derivatives are nowadays used (vinorelbine, vindesine, vinfosiltine, vinovelbine). These are used either alone or in combination with other antitumor agents thus obtaining a of better destruction of the tumor but also with less 
side effects like toxicity and drug resistance(9).

Camphotecin is also a natural alkaloid first extracted from the bark and the stem of Camphtotheca acuminata's antitumor mechanism is by inhibition of topoisomerase I (10). Because of its low solubility various synthetic derivatives were produced. Among them two were approved and are used for the treatment of lung cancer (topotecan) and colorectal cancer (irinotecan). Other analogues used in clinical trials were: 9-nitrocamptothecin, 9-aminocamptothecin, belotecan, exatecan, DE-310, lurtotecan, gimatecan, diflomotecan, Karenitecin, DB-67 (7-tertbutyldimethylsilyl-10-hydroxy

camptothecin), namitecan, BN80927, DRF1042, MAG-CPT, BAY 38-3441, CRLX101 (IT-101), T-0128, CT-2106, HM910 (HM-910), ZBH-1205 (ZBH1205), but the results were rather weak(11).

Taxanes are other antitumor drugs with promising activity. Their anticancer mechanism is by binding to microtubules but they also have an important role in the division of the cells(12). Paclitaxel is a taxane extracted from Taxus brevifloria and is insoluble in water but it has a high lipophilicity. Its anticancer activity proved to be efficient for the treatment of: lung, ovarian and breast cancers, but is effective also for other solid tumors. The mechanism of action of this paclitaxel is through the targeting of DNA repair and cell proliferation. Because the biosynthesis of this taxane is complex 2 semi-synthetic derivatives were developed. Those are docetaxel and cabazitaxel (13).

Docetaxel is a semi-synthetic taxane with the same mechanism of action as paclitaxel. The drug has a different pharmacokinetics and side effects. It is used successfully for the treatment of prostate, non-small cell lung cancer, ovarian and breast cancers(14).

Cabazitaxel is another semi-synthetic taxane with a better cytotoxicity and effectiveness in taxane-resistant patients. It is used for the treatment of the patients with metastatic prostate cancer but also of those who have tumors which are resistant at the treatment with docetaxel or paclitaxel(15).

Etoposide is an epipodophyllotoxin (a semisynthetic product) extracted from the mandrake plant Podophyllum peltatam. The drug is a topoisomerase II inhibitor used for the treatment of small-cell lung cancer, ovarian and testicular cancers, lymphoma, acute myeloid leukemia, and so on.

Anthracyclines are aromatic polyketides mainly produced by Streptomyces (peucetius, caesius, purpurascens, galilaeus, nogalater, and so on). Among the drugs which are a part of the class are: doxorubicin, daunorubicin, adrimycin, carminemycin, aclarubicin. Their activity proved to be efficient against leukemia, melanoma and other tumors. Of course, during the years new hybrid molecules with less adverse effects, like the cardiotoxicity were discovered. Among 
them are: 11-hydroxyaclcinomycin A, 2amino-11-hydroxyaclacinomycin desoxyerythrolaccin, aloesaponarin II. Epirubicin is another semisynthetic anthracycline also produced by genetic engineering(16).

Bleomycin is an anti-tumor compound mainly produced by Steptoalluteichus hindustanus. The drug was mainly used for treating small cell lung cancer, Hodgkin's lymphoma, or testicular cancer. However, in his case there several derivatives like Blenoxane used nowadays(17).

The first inhibitors of angiogenesis drugs used as antitumor agents was Fumagilin a substance produced by Aspergillus fumigatis. It was followed by ovalacin. Of course analogues like TNP470 were next in use(18).

Rapamycin, an immunosuppressive agent mainly used for organ transplantation is a sirolimus derivative which inhibits the mammalian target of rapamycin. The substance has antitumor activity because is capable to induce apoptosis and to inhibit angiogenesis. Similar drugs are: temsirolimus, everolimus, and deforolimus(19).

Novel anticancer medicines based on natural products

Berberine an alkaloid extracted from Rhizoma Coptidis has anticancer effects: inhibits the proliferation of neoplastic cells, induces endoplasmic reticulum stress, autophagy, inhibits tumor invasion and metastasis although its cytotoxic effect is lower when compared with other alkaloids. The antitumor mechanisms of berberine are rather complicated the substance interfering with cell-cycle arrest and apoptosis, inhibits several enzymes , interacts with DNA or RNA(20).

Evodiamine is an alkaloid extracted from Evodia Rutaecarpa with antiangiogenic, anti-invasion and antimetastatic effects. It also induces the cell cycle arrest or apoptosis both in vitro and in vivo. When compared with other compound its effects are present in lower dosage and it seems that the drug is less toxic. The antitumor mechanisms are correlated with the inhibition of Top I enzyme, caspasedependent and caspase-independent apoptosis, down-regulation of $\mathrm{Bcl} 2$ expression and up-regulation of Bax expression. The drug also acts through the pathway of 3-kinase/Akt/caspase and Fasligand/NF-kB signaling pathways in order to induce tumor cell death(8).

Matrine is an alkaloid extracted from Sophora plant with anticancer effects. The main anticancer mechanism is through the mediation of $\mathrm{G} 1$ cell cycle arrest or apoptosis. The drug also has antiangiogenic properties(21).

Piperine is an alkaloid isolated from Piper longum or Piper negrum with the capacity of inhibition of some solid tumors and with anti-metastatic properties. It also inhibits cell invasion. The most important anticancer mechanism ids through the 
induction of apoptosis increasing the percentage of cells in G2/M phase(22).

Sanguinarine is an alkaloid extracted from Sanguinaria Canadensis, and Chelidonium majus. The drug has anticancer properties and induces cell cycle arrest or apoptosis but it also has antiangiogenic effects. The main anti-tumor activity of the alkaloid is the result of its ability to interact with the glutathione. However the sanguinarine is able to inhibit the mitogen-activated protein kinase phosphatase 1, and also can inhibit the induction od DNA damage, Top II, the nucleocytoplasmic trafficking of D1, the signal transducer and activator of transcription 3 activation(STAT 3), modulates the members of $\mathrm{Bcl} 2$ family, down- regulates CDKs cyclins, upregulates p21, p27, and so on(23).

Tetrandine is an alkaloid isolated from Staphania tetranda with antitumor effects. It is capable of induces the different phases of cell cycle arrest and apoptosis. It also has anti-metastatic effects proved in vivo, and in association with other chemotherapeutic agents (doxorubicin, vincristine, paclitaxel, docetaxel) enhances their anti-cancer activity. The drug is also capable of increasing the sensitivity to radiation in various cancer cells. The antitumor effects of tetrandine are the result of generation of ROS, activation of glycogen synthase kinase, of p38 mitogenactivated protein-kinase and inhibition of Wnt/beta-catenin signaling(24).

\section{Antimitotic}

combretastatins, agents like pterocarpans are also new antitumor agents.

Combrestatins were first extracted from Combetum caffrum. CA-4 inhibits tubulin polymerization. It's analogues like LaSSBio-1586 exhibits a better cytotoxicity and has antiproliferative effect both in vitro and in vivo(25).

Withanolides are secondary metabolites found in the family of Solanaceae. Withaferin A was first extracted from Withania somnifera. The drug inhibits the growth of tumor cells through many mechanisms. Withaphysalins was isolated from Acnistus arborescens(26).

Pterocarpans are a large group of isoflavonoids. The drugs are extracted from several plant families. Among the substances of this class is 2,3,9trimethoxypterocarpan which proved to have cytostatic activity in leukemia and breast adenocarcinoma cells(27).

Flavones and flavonoids are secondary metabolites extracted from a wide range of plants (fruits, grains, vegetables, and so on) which proved to be efficient for the treatment of several tumors. The semisynthetic derivatives like Flavopiridol had antitumor activity against esophageal ang gastric tumor cells(28). Other drugs from the same class are potent against breast, lung colorectal cancer cells(29). 
Saffron represents the dried stigmas of Crocus sativus. The plant is very expensive and it is mainly cultivated in countries like Iran, Turkey, Greece, Spain, France, Israel, Pakistan, India, New Zeeland, Japan, and so on. The most important secondary metabolites of saffron are crocin and crocetin. Crocin, the most important one seems to be very efficient with low toxicity on the cells(30). The substance proved to have anticancer effects both in vitro and in vivo. The mechanism are by the inhibition of invasion, of metastasis, targeting microtubules and induction of apoptosis(31, 32). It's antitumor effect was demonstrated on breast, lung, leukemic, pancreatic cancer cells(33). Also, saffron had cytotoxic effect on skin cancer, cervical cancer, gastric and colorectal cancer or hepatic cancer(34).

Curcumin is a drug extracted from the rhizomes of Curcuma longa. It has a polyphenolic structure. The substance proved to have antineoplastic properties and, very important no toxicity on nonmalignant cells(35). Turmeric demonstrated to have antiproliferative, antimetastatic, antiangiogenic and antimutagenic effect on many tumors like: breast, colon, kidney, prostate, skin, but also on glioblastomas(36). In 2015 we demonstrated that Curcumin has an antiproliferative effect on low-passage glioblastoma cells in vitro(37). We also demonstrated the capability of the drug to induce apoptosis in glioblastoma cells. Actually, the drug was also tested in a number of phase I and Phase II clinical studies for breast cancer, colon cancer, pancreatic cancer, multiple myeloma. The substance proved to be efficient despite its limited systemic bioavailability(38).

Epigallocatechin gallate is extracted from the plant Camellia sinensis, a green tea. Green tea is very rich in catechins and among them epigallocatechin gallate is the most encountered. The drug had antiproliferative, anti-apoptotic, antimetastatic effect on several tumors like: prostate, pancreas, liver, breast, lung, skin, and so on(39). It's effects were demonstrated both in vitro and in vivo. However, the results of clinical trials were rather contradictory. Epigallocatechin gallate proved to be efficient in patients with prostate cancer or chronic lymphocytic leukemia with minimum adverse effects(40). Its combination with other anticancer drugs may bring more benefits for the patients(41).

Resveratrol is a substance extracted from plants like: Veratrum grandiflorum, Polygonum cuspidatum, grapes, peanuts, or mulberries. The polyphenol has proved to have anti-cancer properties in tumors like: skin, colon, esophageal(42). Actually the drug has antiproliferative, antiangiogenic, antimetastatic, antiapoptotic effects both in vitro and in vivo(43). The studies which involved healthy subjects along with those which involved patients with colon cancer proved that resveratrol is more efficient in cancer 
prevention, but however more research needs to be done(44).

Indole-3-carbinole is extracted from plants like: cabbage, broccoli, cauliflower, Brussels sprouts. The substance proved to have also anti-cancer properties. It has the capacity to inhibit the growth of various tumor cells like: breast, ovarian, liver, colon, lung(45). Indole-3-carbinol can inhibit the cell growth, metastasis, angiogenesis, apoptosis(46). In clinical trials the drug was used to treat hormone responsive cancers. The drug proved to be effective and with minimum adverse effects and a good tolerability(47).

\begin{tabular}{|c|c|c|c|}
\hline $\begin{array}{c}\text { ANTICANCER } \\
\text { MEDICINES BASED } \\
\text { ON NATURAL } \\
\text { PRODUCTS } \\
\end{array}$ & CLASS & $\begin{array}{l}\text { NATURAL } \\
\text { PRODUCTS }\end{array}$ & $\begin{array}{l}\text { SEMI-SYNTHETIC } \\
\text { PRODUCTS }\end{array}$ \\
\hline Current alkaloids & Vinka alkaloids & $\begin{array}{l}\text { Vincristine } \\
\text { Vinblastine }\end{array}$ & $\begin{array}{l}\text { Vinorelbine } \\
\text { Vindesine } \\
\text { Vinfosiltine } \\
\text { Vinovelbine }\end{array}$ \\
\hline & Camphotecin & Camphotecine & $\begin{array}{l}\text { 9-nitrocamphotecin } \\
\text { 9-aminocamphotecin } \\
\text { Belotecan } \\
\text { Exotecan } \\
\text { Lurtotecan } \\
\text { DE-310 } \\
\text { Gimatecan } \\
\text { Diflomotecan } \\
\text { Karenitecin } \\
\text { DB-67, so on }\end{array}$ \\
\hline Current taxanes & Taxanes & Paclitaxel & $\begin{array}{l}\text { Docetaxel } \\
\text { Cabazitaxel }\end{array}$ \\
\hline Current antracyclines & Antracyclines & $\begin{array}{l}\text { Doxorubicin } \\
\text { Daunorubicin } \\
\text { Adriamycin } \\
\text { Carminemycin } \\
\text { Aclarubicyn }\end{array}$ & $\begin{array}{l}\text { 11-hydroxyaclacinomycin } \\
\text { 2-amino-11- } \\
\text { hydroxyaclacinomycin } \\
\text { Desoxyerythrolaccin } \\
\text { Aloesaponarin II } \\
\text { Epirubicin }\end{array}$ \\
\hline Current bleomycin & Bleomycin & Bleomycin & Blenoxane \\
\hline $\begin{array}{l}\text { Current inhibitors of } \\
\text { angiogenesis }\end{array}$ & $\begin{array}{l}\text { Inhibitors } \\
\text { angiogenesis }\end{array}$ & Fumagilin & $\begin{array}{l}\text { Ovalacin } \\
\text { TNP470 }\end{array}$ \\
\hline Current rapamycin & Rapamycin & Rapamycin & $\begin{array}{l}\text { Temsirolimus } \\
\text { Everolimus } \\
\text { Deforolimus }\end{array}$ \\
\hline Novel alkaloids & Alkaloids & $\begin{array}{l}\text { Berberine } \\
\text { Evodiamine } \\
\text { Matrine } \\
\text { Piperine } \\
\text { Sanguinarine } \\
\text { Tetrandine }\end{array}$ & \\
\hline $\begin{array}{l}\text { Novel antimitotic } \\
\text { agents }\end{array}$ & $\begin{array}{l}\text { Antimitotic } \\
\text { agents }\end{array}$ & $\begin{array}{l}\text { Combrestatins } \\
\text { Withanolides }\end{array}$ & \\
\hline \multirow[t]{7}{*}{ Novel isoflavonoids } & Isoflavonoids & Pterocarpans & \\
\hline & $\begin{array}{l}\text { Flavones and } \\
\text { flavonoids }\end{array}$ & Flavopiridol & \\
\hline & Saffron & $\begin{array}{l}\text { Crocin } \\
\text { Crocetin }\end{array}$ & \\
\hline & Curcumin & Curcumin & \\
\hline & $\begin{array}{l}\text { Epigallocathechin } \\
\text { gallate }\end{array}$ & $\begin{array}{l}\text { Epigallocathechin } \\
\text { gallate }\end{array}$ & \\
\hline & Resveratrol & Resveratrol & \\
\hline & Indole-3-carbinol & Indole-3-carbinol & \\
\hline
\end{tabular}

Table 1 Anticancer medicines based on natural products 


\section{Conclusions}

In conclusion, although more extensive research is to be done, phyto molecules represent a good option for the future cancer treatment possibilities. Their efficacy is given by the high biocompatibility and low cost.

\section{Conflict of interest}

The authors declare no conflict of interest.

\section{References}

1. Suero Molina E, Wolfer J, Ewelt C, Ehrhardt A, Brokinkel B, Stummer W. Dual-labeling with 5aminolevulinic acid and fluorescein for fluorescenceguided resection of high-grade gliomas: technical note. Journal of neurosurgery. 2017:1-7. https://doi.org/10.3171/2016.11.JNS161072

2. Institute NC. Cancer statistics April 27, 2018. [Available from: https://www.cancer.gov/aboutcancer/understanding/statistics].

3. Aggarwal BB, Danda D, Gupta S, Gehlot P. Models for prevention and treatment of cancer: problems vs promises. Biochem Pharmacol. 2009;78(9):1083-94. https://doi.org/10.1016/j.bcp.2009.05.027

4. Bayat Mokhtari R, Homayouni TS, Baluch N, Morgatskaya E, Kumar S, Das B, et al. Combination therapy in combating cancer. Oncotarget. 2017;8(23):38022-43.

https://doi.org/10.18632/oncotarget.16723

5. Tariq A, Sadia S, Pan K, Ullah I, Mussarat S, Sun F, et al. A systematic review on ethnomedicines of anticancer plants. Phytother Res. 2017;31(2):202-64. https://doi.org/10.1002/ptr.5751

6. Williams WOFTLLDA. Foye's principles of medicinal chemistry. 6th, editor: Philadelphia : Lippincott Williams \& Wilkins, (C2008; 2008.

7. Wang X, Song Y, Su Y, Tian Q, Li B, Quan J, et al. Are PEGylated liposomes better than conventional liposomes? A special case for vincristine. Drug Deliv. 2016;23(4):1092-100. https://doi.org/10.3109/10717544.2015.1027015
8. Fei XF, Wang BX, Li TJ, Tashiro S, Minami M, Xing DJ, et al. Evodiamine, a constituent of Evodiae Fructus, induces anti-proliferating effects in tumor cells. Cancer Sci. 2003;94(1):92-8. https://doi.org/10.1111/j.1349-7006.2003.tb01358.x

9. Almagro L, Fernandez-Perez F, Pedreno MA. Indole alkaloids from Catharanthus roseus: bioproduction and their effect on human health. Molecules. 2015;20(2):2973-3000. https://doi.org/10.3390/molecules20022973

10. Arakawa $\mathrm{Y}$, Ozaki K, Okawa $\mathrm{Y}$, Yamada H. Three missense mutations of DNA topoisomerase I in highly camptothecin-resistant colon cancer cell sublines. Oncol Rep. 2013;30(3):1053-8. https://doi.org/10.3892/or.2013.2594

11. Li F, Jiang T, Li Q, Ling X. Camptothecin (CPT) and its derivatives are known to target topoisomerase I (Top1) as their mechanism of action: did we miss something in CPT analogue molecular targets for treating human disease such as cancer? Am J Cancer Res. 2017;7(12):2350-94

12. Ojima I, Lichtenthal B, Lee S, Wang C, Wang X. Taxane anticancer agents: a patent perspective. Expert Opin Ther Pat. 2016;26(1):1-20. https://doi.org/10.1517/13543776.2016.1111872

13. Barbuti AM, Chen ZS. Paclitaxel Through the Ages of Anticancer Therapy: Exploring Its Role in Chemoresistance and Radiation Therapy. Cancers (Basel).2015;7(4):2360-71. https://doi.org/10.3390/cancers7040897

14. Wen G, Qu XX, Wang D, Chen XX, Tian XC, Gao F, et al. Recent advances in design, synthesis and bioactivity of paclitaxel-mimics. Fitoterapia. 2016;110:26-37.

https://doi.org/10.1016/j.fitote.2016.02.010

15. Vrignaud P, Semiond D, Benning V, Beys E, Bouchard H, Gupta S. Preclinical profile of cabazitaxel. Drug Des Devel Ther. 2014;8:1851-67. https://doi.org/10.2147/DDDT.S64940

16. Madduri K, Kennedy J, Rivola G, Inventi-Solari A, Filippini $S$, Zanuso $G$, et al. Production of the antitumor drug epirubicin (4'-epidoxorubicin) and its precursor by a genetically engineered strain of Streptomyces peucetius. Nat Biotechnol. 1998;16(1):69-74. https://doi.org/10.1038/nbt0198-69

17. Tao M, Wang L, Wendt-Pienkowski E, Zhang N, Yang $\mathrm{D}$, Galm U, et al. Functional characterization of $\mathrm{t} \mathrm{mH}$ in Streptoalloteichus hindustanus E465-94 ATCC 31158 unveiling new insight into tallysomycin biosynthesis and affording a novel bleomycin analog. Mol Biosyst. 
2010;6(2):349-56.

https://doi.org/10.1039/B918106G

18. Sasaki A, Alcalde RE, Nishiyama A, Lim DD, Mese H, Akedo $\mathrm{H}$, et al. Angiogenesis inhibitor TNP-470 inhibits human breast cancer osteolytic bone metastasis in nude mice through the reduction of bone resorption. Cancer Res. 1998;58(3):462-7.

19. Rini B, Kar S, Kirkpatrick PT. Nature Rev. Drug Discov.2007;6:599-600. https://doi.org/10.1038/nrd2382

20. Diogo CV, Machado NG, Barbosa IA, Serafim TL, Burgeiro A, Oliveira PJ. Berberine as a promising safe anti-cancer agent - is there a role for mitochondria? Curr Drug Targets. 2011;12(6):850-9. https://doi.org/10.2174/138945011795528930

21. Liu T, Song $Y$, Chen $H$, Pan S, Sun X. Matrine inhibits proliferation and induces apoptosis of pancreatic cancer cells in vitro and in vivo. Biol Pharm Bull. 2010;33(10):1740-5.

https://doi.org/10.1248/bpb.33.1740

22. Srinivasan K. Black pepper and its pungent principlepiperine: a review of diverse physiological effects. Crit Rev Food Sci Nutr. 2007;47(8):735-48. https://doi.org/10.1080/10408390601062054

23. Kim S, Lee TJ, Leem J, Choi KS, Park JW, Kwon TK. Sanguinarine-induced apoptosis: generation of ROS, down-regulation of Bcl-2, c-FLIP, and synergy with TRAIL. J Cell Biochem. 2008;104(3):895-907. https://doi.org/10.1002/jcb.21672

24. Sun XC, Cheng HY, Deng YX, Shao RG, Ma J. Tetrandrine: a potent abrogator of $\mathrm{G} 2$ checkpoint function in tumor cells and its mechanism. Biomed Environ Sci. 2007;20(6):495-501.

25. Lauritano $\mathrm{C}$, Andersen $\mathrm{JH}$, Hansen $\mathrm{E}$, Albrigtsen $\mathrm{M}$, Escalera L, Esposito $F$, et al. Bioactivity screening of microalgae for antioxidant, anti-inflammatory, anticancer, anti-diabetes, and antibacterial activities. Frontiers in Marine Science. 2016;3:68. https://doi.org/10.3389/fmars.2016.00068

26. Roy RV, Suman S, Das TP, Luevano JE, Damodaran C. Withaferin A, a steroidal lactone from Withania somnifera, induces mitotic catastrophe and growth arrest in prostate cancer cells. J Nat Prod. 2013;76(10):1909-15. https://doi.org/10.1021/np400441f

27. Militao GC, Prado MP, Pessoa C, de Moraes MO, Silveira ER, Lima MA, et al. Pterocarpans induce tumor cell death through persistent mitotic arrest during prometaphase. Biochimie. 2014;104:147-55. https://doi.org/10.1016/j.biochi.2014.06.005
28. Rathkopf D, Dickson MA, Feldman DR, Carvajal RD, Shah MA, Wu N, et al. Phase I study of flavopiridol with oxaliplatin and fluorouracil/leucovorin in advanced solid tumors. Clin Cancer Res. 2009;15(23):7405-11. https://doi.org/10.1158/1078-0432.CCR-09-1502

29. Wen L, Wu D, Jiang Y, Prasad KN, Lin S, Jiang G, et al. Identification of flavonoids in litchi (Litchi chinensis Sonn.) leaf and evaluation of anticancer activities. Journal of functional foods. 2014;6:555-63. https://doi.org/10.1016/i.jf.2013.11.022

30. Abdullaev FI, Espinosa-Aguirre JJ. Biomedical properties of saffron and its potential use in cancer therapy and chemoprevention trials. Cancer Detect Prev.2004;28(6):426-32. https://doi.org/10.1016/i.cdp.2004.09.002

31. Tarantilis PA, Morjani $H$, Polissiou M, Manfait M. Inhibition of growth and induction of differentiation of promyelocytic leukemia (HL-60) by carotenoids from Crocus sativus L. Anticancer Res. 1994;14(5A):19138.

32. Patel S, Sarwat M, Khan TH. Mechanism behind the anti-tumour potential of saffron (Crocus sativus L.): The molecular perspective. Crit Rev Oncol Hematol. 2017;115:27-35.

https://doi.org/10.1016/i.critrevonc.2017.04.010

33. Nair SC, Pannikar B, Panikkar KR. Antitumour activity of saffron (Crocus sativus). Cancer Lett. 1991;57(2):109-14. https://doi.org/10.1016/0304-3835(91)90203-T

34. Bhandari PR. Crocus sativus L. (saffron) for cancer chemoprevention: A mini review. J Tradit Complement Med.2015;5(2):81-7. https://doi.org/10.1016/j.jtcme.2014.10.009

35. Ravindran J, Prasad S, Aggarwal BB. Curcumin and cancer cells: how many ways can curry kill tumor cells selectively? AAPS J. 2009;11(3):495-510. https://doi.org/10.1208/s12248-009-9128-x

36. Epstein J, Sanderson IR, Macdonald TT. Curcumin as a therapeutic agent: the evidence from in vitro, animal and human studies. Br J Nutr. 2010;103(11):1545-57. https://doi.org/10.1017/S0007114509993667

37. Artene S, Folcuti C, DRICU A. $\beta$-arrestin 1 Overexpression Increases Temozolomide Resistance in Human Malignant Glioma Cells. Current health sciences journal. 2017;43(2):112.

38. Sharma RA, Euden SA, Platton SL, Cooke DN, Shafayat A, Hewitt HR, et al. Phase I clinical trial of oral curcumin: biomarkers of systemic activity and compliance. Clin Cancer Res. 2004;10(20):6847-54. https://doi.org/10.1158/1078-0432.CCR-04-0744 
39. Nagle DG, Ferreira D, Zhou Y-D. Epigallocatechin-3gallate (EGCG): chemical and biomedical perspectives. Phytochemistry. 2006;67(17):1849-55. https://doi.org/10.1016/j.phytochem.2006.06.020

40. Pisters KM, Newman RA, Coldman B, Shin DM, Khuri FR, Hong WK, et al. Phase I trial of oral green tea extract in adult patients with solid tumors. J Clin Oncol. 2001;19(6):1830-8.

https://doi.org/10.1200/JCO.2001.19.6.1830

41. Stearns ME, Wang M. Synergistic Effects of the Green Tea Extract Epigallocatechin-3-gallate and Taxane in Eradication of Malignant Human Prostate Tumors. Transl Oncol. 2011;4(3):147-56. https://doi.org/10.1593/tlo.10286

42. Signorelli $P$, Ghidoni R. Resveratrol as an anticancer nutrient: molecular basis, open questions and promises. J Nutr Biochem. 2005;16(8):449-66. https://doi.org/10.1016/j.jnutbio.2005.01.017

43. Bove K, Lincoln DW, Tsan MF. Effect of resveratrol on growth of 4T1 breast cancer cells in vitro and in vivo. Biochem Biophys Res Commun. 2002;291(4):1001-5. https://doi.org/10.1006/bbrc.2002.6554
44. Nguyen AV, Martinez M, Stamos MJ, Moyer MP, Planutis K, Hope C, et al. Results of a phase I pilot clinical trial examining the effect of plant-derived resveratrol and grape powder on Wnt pathway target gene expression in colonic mucosa and colon cancer. Cancer Manag Res. 2009;1:25-37. https://doi.org/10.2147/CMAR.S4544

45. Aggarwal BB, Ichikawa $\mathrm{H}$. Molecular targets and anticancer potential of indole-3-carbinol and its derivatives. Cell Cycle. 2005;4(9):1201-15. https://doi.org/10.4161/cc.4.9.1993

46. Verhoeven DT, Verhagen $H$, Goldbohm RA, van den Brandt PA, van Poppel G. A review of mechanisms underlying anticarcinogenicity by brassica vegetables. Chem Biol Interact. 1997;103(2):79-129. https://doi.org/10.1016/S0009-2797(96)03745-3

47. Reed GA, Peterson KS, Smith HJ, Gray JC, Sullivan DK, Mayo MS, et al. A phase I study of indole-3carbinol in women: tolerability and effects. Cancer Epidemiol Biomarkers Prev. 2005;14(8):1953-60. https://doi.org/10.1158/1055-9965.EPI-05-0121 